Western Washington University Western CEDAR

Sociology

Social and Behavioral Sciences

Summer 2010

\title{
Family Life Course Statuses and Transitions: Relationships with Health Limitations
}

Jay Teachman

Western Washington University, jay.teachman@wwu.edu

Follow this and additional works at: https://cedar.wwu.edu/sociology_facpubs

Part of the Sociology Commons

\section{Recommended Citation}

Teachman, Jay, "Family Life Course Statuses and Transitions: Relationships with Health Limitations" (2010). Sociology. 5. https://cedar.wwu.edu/sociology_facpubs/5

This Article is brought to you for free and open access by the Social and Behavioral Sciences at Western CEDAR. It has been accepted for inclusion in Sociology by an authorized administrator of Western CEDAR. For more information, please contact westerncedar@wwu.edu. 


\section{@SAGE}

\section{Pacific Sociological Association}

\section{Family Life Course Statuses and Transitions: Relationships With Health Limitations}

Author(s): Jay Teachman

Source: Sociological Perspectives, Vol. 53, No. 2 (Summer 2010), pp. 201-220

Published by: University of California Press

Stable URL: http://www.jstor.org/stable/10.1525/sop.2010.53.2.201

Accessed: $27 / 10 / 2014$ 17:23

Your use of the JSTOR archive indicates your acceptance of the Terms \& Conditions of Use, available at http://www.jstor.org/page/info/about/policies/terms.jsp

JSTOR is a not-for-profit service that helps scholars, researchers, and students discover, use, and build upon a wide range of content in a trusted digital archive. We use information technology and tools to increase productivity and facilitate new forms of scholarship. For more information about JSTOR, please contact support@ jstor.org. 


\title{
FAMILY LIFE COURSE STATUSES AND TRANSITIONS: RELATIONSHIPS WITH HEALTH LIMITATIONS
}

\author{
JAY TEACHMAN \\ Western Washington University
}

\begin{abstract}
In this study, the author uses 25 years of data taken from the 1979 National Longitudinal Study of Youth to examine the relationship between family life course statuses and transitions and work-related health limitations. The author uses a detailed set of statuses and transitions that include marriage, divorce, cohabitation, and parenthood. The measures of health used tap health limitations in the kind and amount of work that can be performed. Using a fixed-effects estimator for dichotomous outcomes, the author finds that marriage is positively related to the health of men but negatively related to the health of women. The author also finds that parenthood is not related to the health of men but is positively related to the health of women. The results also indicate that statuses are more important for determining health limitations than are transitions.

Keywords: family life course, health, nlsy79
\end{abstract}

Change in the family life of Americans has been substantial over the past three decades. Declining rates of marriage, stably high rates of marital disruption, and high rates of nonmarital cohabitation and out-of-wedlock childbearing have all acted to alter the life course of American men and women (Teachman, Tedrow, and Crowder 2000). Researchers have begun to document the consequences of these changes for the well-being of both parents and children (Amato 2000; Amato and Booth 1997; Popenoe 1996; Waite 1995), including linkages made between family statuses and transitions and levels of mental and physical health (Wood, Goesling, and Avellar 2007). In this article, I contribute to this literature by using longitudinal data taken from the 1979 National Longitudinal Study of Youth (NLSY-79) to examine the association between detailed components of the family life course and physical health. I improve upon prior research by using data that cover a 25-year period of the early adult life course, simultaneously using a more inclusive definition of family statuses and transitions, controlling for selectivity, and considering differences that occur according to both race and sex. I find that variations

Address correspondence to: Jay Teachman, Department of Sociology, Western Washington University, Bellingham, WA 98225; e-mail: Jay.Teachman@wwu.edu.

Sociological Perspectives, Vol. 53, Issue 2, pp. 201-219, ISSN 0731-1214, electronic ISSN 1533-8673.

(c) 2010 by Pacific Sociological Association. All rights reserved. Please direct all requests for permission to photocopy or reproduce article content through the University of California Press's Rights and Permissions website, at http://www.ucpressjournals.com/reprintinfo.asp. DOI: 10.1525/sop.2010.53.2.201. 
in family statuses and transitions are significantly related to changes in physical health in ways that vary according to both sex and race.

\section{EMPIRICAL FOUNDATIONS}

A more substantial body of literature has linked marriage and marital transitions to mental health than has been the case for physical health, finding that marriage benefits mental health while divorce harms mental health (Wood et al. 2007). The limited research tying the family life course to physical health has generally been consistent in finding that a major transition, divorce, has negative effects on physical health (Lorenz, Wickrama, Conger, and Elder 2006; Meadows, McLanahan, and Brooks-Gunn 2008; Williams and Umberson 2004; Wu and Hart 2002; Zhang and Hayward 2006). The literature concerning the relationship between current marital status and physical health is less consistent though, with some research finding a positive effect of being married (Waldron, Weiss, and Hughes 1998) and other research finding either no effect (Williams and Umberson 2004) or a negative effect (Wu and Hart 2002).

In part, these discrepancies may be explained by researchers using different databases covering different segments of the American population and using different measures of physical health. Another source of differences, however, rests in the extent to which complexity in the family life course is fully considered. Some prior research has focused solely on the effects of a single transition, divorce (Lorenz et al. 2006), while other research has concentrated on statuses such as marriage (Waldron et al. 1998; Williams, Sassler, and Nicholson 2008) or cohabitation (Wu, Penning, Pollard, and Hart 2003), ignoring transitions into and out of these statuses. Still other research has focused on both statuses and transitions but ignores nonmarital cohabitation (Bennett 2006), which has become an increasingly important component of the family life course. Only a handful of studies consider the effects of both marital and nonmarital statuses and transitions (Meadows et al. 2008; $\mathrm{Wu}$ and Hart 2002). Furthermore, much of the prior literature has failed to account for the potential effects of selectivity, something to which I pay close attention.

The prior research on physical health also varies considerably with respect to whether the potential effects of parenthood are considered. A limited body of research has shown links between parenthood and physical health without considering the effects of marital status and marital transitions (Mirowsky 2002; 2006). Most of the research considering the effects of marital status or marital transitions on physical health ignores parenthood. Waldron et al. (1998) consider the effects of both marital and parental statuses on physical health but ignore the potential effects of marital status transitions. Only Wu and Hart (2002) investigate the relationships between marital status, marital status transitions, parenthood, and physical health.

Failing to simultaneously consider multiple dimensions of the family life course provides a limited and potentially biased view of the effects of marital status, marital status transitions, and parenthood on health. Young men and women today experience very complex family life course patterns (Amato, Landale, HavasevichBrooks, Booth, Eggebeen, Schoen, and McHale 2008). Nonmarital cohabitation and nonmarital childbearing are increasingly important components of the family life course and are closely interwoven with patterns of marriage and divorce. 
Another limitation of previous research involves short time horizons. As an outcome, physical health is something that evolves over a longer period of time than may be the case for outcomes such as emotional stress, depression, and happiness. Research involving shorter periods of time may therefore fail to find effects of family statuses and transitions on physical health, especially among younger populations. Such research also fails to follow individuals both before and after they experience family life course statuses and transitions. Much of the previous research linking physical health and the family life course uses data that cover only a few years. For example, Wu and Hart (2002) use Canadian data that cover a 3-year period of time. Meadows et al. (2008) use data that span 5 years, while Williams and Umberson (2004) use data that span 8 years. The prior literature has also been inconsistent in handling potential variations in the linkages between the family life course and health that may occur according to race and gender. Some of the previous research focuses solely on women (Lorenz et al. 2006; Meadows et al. 2008; Williams et al. 2008; Williams and Umberson 2004), while little previous research considers how theses linkages may vary according to race (Beckett and Elliott 2002).

\section{THEORY}

Several theoretical positions have been proposed to explain the link between health and family statuses and transitions, including resource theory, stress theory, and selectivity. I briefly discuss each in turn, including why relationships might vary according to sex and race. My purpose is to outline a rationale for why family statuses and transitions might affect health rather than an adjudication between various theoretical positions.

\section{Social and Economic Resources}

Resource theory argues that economic and social resources (often in the form of social control of behavior) known to be linked to health vary according to family statuses, including marital status and parenthood (Depner and Ingersoll-Dayton 1985; Meadows et al. 2008; Umberson 1987; Williams and Umberson 2004; Wu and Hart 2002). Prior research has generally found that married persons have access to more economic and social resources that enhance their health than do never-married and divorced persons (Ross 1995; Ross, Mirowsky, and Goldsteen 1990; Wyke and Ford 1992). These resources include higher family income, an extended set of friendships, support and nurturing during times of stress, and mutual monitoring of healthrelated behaviors like smoking, drinking, and excessive eating (Waite 1995).

The relationship between cohabitation and physical health is less well established. The available literature suggests, however, that cohabitors report lower levels of mental health than do individuals who are married (Brown 2000; Ross 1995). The weaker relationship between cohabitation and positive health may stem from the fact that reciprocal care taking is less likely to occur in cohabiting relationships (Manning and Smock 2002; Peters and Liefbroer 1997), as well as the fact that cohabitors exhibit less social integration in close networks of kin (Marcussen 2005; Nock 1995) 
and have fewer economic resources (Waite 1995). This pattern is reflected in the fact that compared to married persons cohabitors are more likely to report mental illness, substance abuse, and violence (DeKlyen, Brooks-Gunn, McLanahan, and Knab 2006; Kenney and McLanahan 2006).

The link between parenthood and physical health is also less well substantiated. Most of the prior research has focused on the effects of parenthood on mental health (Evenson and Simon 2005; Nomaguchi and Milkie 2003), often finding mixed effects. Theoretically, however, parenthood has been linked to increases in social resources via social integration and expanded friendship networks (Gallagher and Gerstel 2001; Nomaguchi and Milkie 2003), which should act to improve health. Parents may also seek to limit their participation in unhealthy behaviors (or are constrained from doing so by the burdens of parenthood) that might reduce their health and subsequently jeopardize the well-being of their children. At the same time, parenthood involves a number of daily strains (less leisure time, reduced sleep, increased likelihood of role overload and conflict, and reduced marital quality) that may serve to decrease health (Glass and Fujimoto 1994; Goldsteen and Ross 1989; Nomaguchi and Milkie 2003). Thus, the direction of the relationship between health and parenthood is theoretically indeterminate. The limited empirical evidence suggests that parenthood reduces the number of health problems experienced by women (Waldron et al. 1998).

\section{Variations According to Sex and Race}

The empirical evidence suggests that marriage is more beneficial to the health of men than women (Hu and Goldman 1990; Lillard and Waite 1995; Rogers 1995). This effect may be tied to the fact that women are more likely to maintain strong social ties as they age irrespective of their marital status (Gerstel 1988; Turner 1994) and that within marriage men are more likely than women to receive feedback regulating their health behaviors (Umberson 1992). This point is important to note because unmarried men are much more likely than married men to engage in risky health behaviors such as heavy drinking and drug use (Umberson 1987). As a consequence, unmarried men are more likely than married men to possess biomarkers of cardiovascular disease such as high blood pressure and elevated cholesterol levels (Beckett and Elliott 2002).

Contrary to the case for marriage, parenthood may be more important to the health of women than men. Women still provide the majority of childcare (Sayer, Bianchi, and Robinson 2004), and motherhood remains a master status for women (McQuillan, Greil, White, and Jacob 2003), making it more salient to them. Nomaguchi and Milkie (2003) find that parenthood has strong effects on the lives of women but little effect on the lives of men (but see Evenson and Simon 2005 for conflicting evidence).

Variations in the relationship between marital status and health according to race have been less well studied than those linked to sex, but the way in which blacks and whites experience family roles may affect this relationship. For example, black women have a longer history of being employed outside the home than white women (Landry 2000). Black women are also more likely to be economic providers 
when married (Broman 1991). Other evidence indicates that black women experience lower levels of distress when family and work obligations interfere with each other (Marcussen and Piatt 2005). These findings imply that marriage may not be as consequential for the health of black women compared to white women because the economic and social resources available to them may not be as closely tied to marriage.

\section{Transitions as Stressors}

A second theoretical perspective is stress theory. In this perspective it is not the family status occupied that matters but the stress associated with a transition that leads to that status. For example, economic losses, emotional loss, and disruption of social networks associated with divorce increase levels of stress, which have in turn been linked to reductions in mental and physical health (Lorenz et al. 2006; Meadows et al. 2008; Williams and Umberson 2004; Wu and Hart 2002). Similarly negative effects of leaving a cohabiting union have been identified (Meadows et al. 2008; Wu and Hart 2002).

Much less is known about the transition into marriage, but the greater resources enjoyed by married persons (both economic and social) suggest that this transition may have positive benefits for health. The limited amount of empirical research does not support this supposition, though. Indeed, the transition to marriage has been shown to have negative effects on health, perhaps reflecting the stresses, even if temporary, associated with substantial lifestyle changes (Meadows et al. 2008).

The transition to parenthood can also be stressful (Belsky and Kelly 1994; Belsky, Lang, and Rovine 1985; Gerdingen and Center 2005). Parenthood often involves the disruption of existing friendship networks, revised work and household schedules, increased financial burdens, and a renegotiation of the household division of labor, which can all increase stress levels (Cowan and Cowan 2000). However, there is no clear empirical relationship between the onset of parenthood and mental health (Evenson and Simon 2005) and the available literature pertaining to the physical health consequences of parenthood transitions is very limited and focuses only on the transition to parenthood, ignoring transitions out of parenthood. In particular, $\mathrm{Wu}$ and Hart (2002) find no evidence that becoming a parent affects the health status of adults. No information is available about the consequences for health that may be associated with children leaving a household. On one hand, a child leaving a household may entail stress associated with losing close contact with a loved one. Children leaving home may also engender stressful changes in personal relationships and a renegotiation of self concept. On the other hand, a childfree lifestyle may substantially reduce stresses associated with parenting and may increase economic resources available to parents.

\section{Variations According to Sex and Race}

Race and sex differences in the relationship between family status transitions and health have been unevenly studied. Again, there is more information available about divorce as a critical transition. Consistent with the notion that marriage 
does more for the health of men than women, research has found that divorce has greater negative health consequences for men than women (Gove and Shin 1989: Williams and Umberson 2004; Wu and Hart 2002). Although empirical evidence is lacking, several authors have suggested that the effects of divorce on health should be smaller for black women compared to white women given the greater incidence of divorce in the black population (reducing the likelihood that divorce carries with it any negative connotations) and the fact that black women are less likely to lose their attachment to the labor force while married, buffering the impact of marital dissolution on their financial and social resources (Beckett and Elliott 2002; Gove and Shin 1989; Ross et al. 1990).

Research on race and sex differences in the effects of changes in cohabitation and parenthood status is virtually nonexistent. Wu and Hart (2002) find that leaving a cohabiting union has similarly negative effects on the health of both men and women. Following the arguments made above for divorce, leaving a cohabiting union may have less impact on the health of black women than white women. Similarly, given the argument made in the previous section that parenthood is a master status for women, parenthood transitions may hold more substantial consequences for women than for men.

\section{Selectivity}

The third theoretical perspective linking family life course transitions and health is selectivity. On one hand, such selectivity may take the form of constant unobserved differences in healthiness, personality, and related factors that might generate differences in the family life course and health outcomes. On the other hand, the linkage between family life course statuses and transitions and health may not be causal. Rather, the observed associations are the result of health status selecting individuals into different family statuses through various transitions. More generally, the literature suggests that healthier individuals are more likely to marry and stay married (Goldman 1993; Joung, van de Mheen, Stronks, van Poppel, and Mackenback 1998; Wade and Pevalin 2004). Arguments about the importance of selectivity in generating the linkages between family statuses and health thus make it imperative that any study postulating an effect of statuses and transitions on health take the potential effects of selectivity into account. Failure to do so runs the risk of attributing a causal interpretation to a relationship when it is not warranted.

\section{Variations According to Sex and Race}

Previous literature suggests that health impacts marital status and that this selection process is different for men and women. Cheung (1998) and Cheung and Sloggett (1998) find that health problems are negatively related to the chances of marriage for both men and women (but more strongly for women), while health problems are negatively related to the chances of divorce for women only (a form of adverse selection). Unfortunately, no prior research has examined race differences in selectivity linking marital status and health. However, substantial 
differences in marital status and health that exist between whites and blacks suggest that differences in selectivity according to race may exist and should be taken into consideration.

Taking into account these theoretical considerations I expand upon the prior literature in several ways. First, I analyze the association between the family life course statuses and transitions and health over a long period of time, covering up to 25 years of the early adult life course, and following individuals from a point prior to which most have had any health problems or had begun their family life course by forming intimate, coresidential relationships or having children. In this fashion, by focusing on family life course statuses and transitions as they affect health status, I am better able to minimize the likelihood of reverse causality. Second, I include measures of family life course statuses and transitions that cover marriage, cohabitation, and parenthood simultaneously. Third, I consider variations in the association between the family life course and health that may occur according to sex and race. Fourth, I use a fixed-effects procedure that minimizes the likelihood that stable, unmeasured characteristics of individuals generate the observed results.

\section{DATA AND METHODS}

Starting in 1979, the NLSY-79 interviewed 12,686 men and women between the ages of 14 and 21. In my analysis, I follow respondents from the time they reach age 18 until 2004 when they are age 43-46. Thus, respondents were interviewed a maximum of twenty-one times over a period spanning 25 years (interviews were annual through 1994, biennial thereafter). From these observations, I create a database consisting of person years where respondents contribute a person year for each round of the NLSY-79 in which they were interviewed. To the extent possible, if a respondent was not interviewed in a particular year but was interviewed in a subsequent year, I used retrospective information collected by the NLSY to complete information for the missing person year. Because I argue for differences in the relationship between the family life course and health according to race and sex, I examine four separate databases consisting of white men $(53,869$ person years, 3,744 individuals), white women (54,743 person years, 3,711 individuals), black men (26,351 person years, 1,615 individuals), and black women $(26,357$ person years, 1,554 individuals).

Respondents who are permanently lost to follow-up, either because they cannot be tracked or because of changes in the sampling frame of the NLSY-79, contribute person years until they exit the survey. The NLSY-79 is also a household survey, and all eligible members of a sampled household are interviewed. Accordingly, there are a number of sibling pairs (or sometimes three or more siblings) in the data used for this article (approximately one-third of the households used in this analysis contained at least two siblings).

Because the NLSY-79 follows respondents over time, as well as includes respondents from the same household, I employ a fixed-effects procedure that controls for all stable, nontransient, individual-level, and household-level characteristics (observed or unobserved) tied to selectivity with respect to family statuses and 
transitions that might bias the relationship between the family life course and health. These stable characteristics could include factors such as personality (e.g., underlying motivation to maintain health, unobserved health habits, work habits), underlying genetic differences in health, family history and tradition related to health and work, and so on.

To measure health status, I consider two questions asked of all respondents in each of the survey years. I use these questions because they are the only healthrelated questions asked in each round of the NLSY-79. Both questions reflect health as it is related to participation in the labor market. The first question is, "(Are you/ would you be) limited in the kind of work you (could) do on a job for pay because of your health?" The second question is, "(Are you/would you be) limited in the amount of work you (could) do because of your health?" Respondents could answer yes or no to both questions. I code the current value $(0=$ no, $1=$ yes $)$ of each variable in each of the intervals for all respondents who have ever experienced a change in health limitations. ${ }^{1}$

Both questions referring to capacity to work are salient to respondents of the ages considered here (I use 18 as the lower age for respondents in order to assure that the question framed in terms of labor market participation is relevant to them). Because the response categories are dichotomous (yes/no), I use a fixedeffects conditional-likelihood logistic regression procedure to examine the relationship between the measured covariates and both measures of health status (Allison 2005; Johnson 2005). The regression results indicate the relationship between the included covariates and health status net of any fixed characteristics (measured or unmeasured) that may be linked to both the family life course and health status.

The family life course of respondents is captured by a set of time-varying dummy variables measuring marital and parental status at the beginning of each person year, as well as a set of time-varying dummy variables that indicate whether a transition into or out of any of these statuses occurred in the prior interval. The family statuses used in the analysis include never married, married, divorced or separated, cohabiting (never married forms the baseline category), and presence of an own child. I do not distinguish between first and higher order unions, nor do I consider number of own children not living in the household. Available sample sizes for higher order statuses and transitions are quite small. Exploratory analyses using measures distinguishing between first and higher order statuses and transitions did not yield evidence of better fitting models.

The transitions used include marriage, divorce, entering a cohabiting union, dissolving a cohabiting union, gaining own child (transitioning from a household without an own child to a household with at least one own child), and losing own child (transitioning from a household with at least one own child to a household without an own child) (no transition forms the baseline category). The term "own child" refers to the presence of a biological, adopted, or step child under age 18 living in the household.

In order to further reduce the influence of selectivity (beyond that afforded by the fixed-effects procedure), I include a number of time-varying control variables in the analysis (fixed covariates cannot be included in any fixed-effects procedure) 
that have been shown to be related to health status in prior research. In particular, the inclusion of these variables helps to minimize the likelihood of selectivity based on transitory characteristics of respondents. These covariates include highest grade of schooling completed as of the beginning of each interval, whether the respondent was enrolled in school as of May of the current interval, the number of weeks worked in the prior interval (measured in weeks), cumulative labor force experience since 1979 as of the beginning of the interval, the logarithm of family income in the prior interval, and age. The controls for past labor market participation (in the past year and cumulative) are important because they reduce the likelihood that health status as measured by ability to participate in the labor market is simply the result of cumulative or transitory health disadvantages that would otherwise limit labor force participation.

\section{DESCRIPTIVE STATISTICS}

Shown in Table 1 are weighted descriptive statistics for respondents separately according to race and sex. The values presented are for person years and represent the average value for each variable over all the person years included for a particular group. In general, women report more health limitations in ability to work than do men, and blacks report more limitations than do whites. In addition, blacks are less likely to be married and more likely to be divorced than whites. Women are much more likely than men to have own children living with them. The control variables also indicate the expected race and sex differences, with men earning more than women and whites earning more than blacks. Men also have more time invested in the labor market than women.

Because the indicators of health used in my analysis have not received prior attention in the literature, validation of their measurement characteristics is in order. Accordingly, Table 2 provides information linking the two measures used in my analysis to more objective and more commonly used measures of health. Results are shown separately by race and sex. The validating measures are taken from a set of health-related questions that are asked of all respondents in the NLSY-79 in the first interview after they turn age 40. These are cross-sectional estimates and thus cannot be used to establish changes in health over time. However, if the two indicators of health used in this analysis are valid, they should correspond to cross-sectional differences in alternative measures of health. The fixed measures of health used include ( 1$)$ a dichotomous indicator $(1=$ yes, $0=$ no) of whether the respondent spends 10 or more minutes per day on health problems ("Do you spend more than 10 minutes a day on your own health problems or conditions, such as preparing and taking medicines, applying treatments, taking care of surgical problems, or doing any kind of rehabilitation?"); (2) an indicator, ranging from $1=$ all of the time to $6=$ some of the time, of whether health problems limit the social activities of the respondent ("During the past 4 weeks, how much of the time has your physical health or emotional problems interfered with your social activities [like visiting with friends, relatives, etc.]?"); (3) an indicator, ranging from $1=$ not limited at all to $3=$ limited a lot, of whether health limits the respondent's ability to climb stairs ("Does your health limit you in your ability to climb several flights 


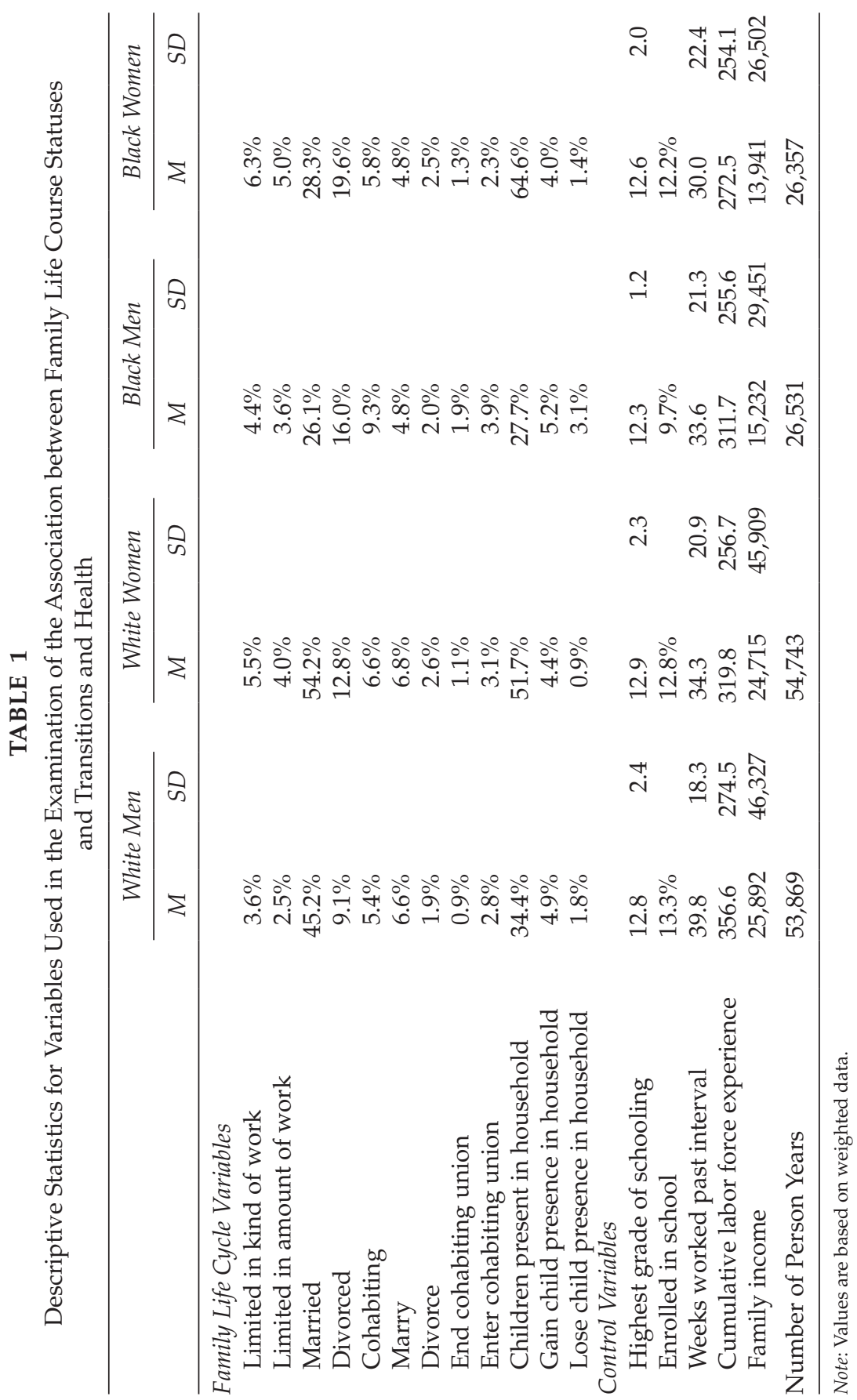


TABLE 2

Association between Variables Indicating Limitations in Amount and Kind of Work and Other Measures of Health Status

\begin{tabular}{|c|c|c|c|c|}
\hline \multirow[b]{3}{*}{ Related Health Concerns } & \multicolumn{4}{|c|}{ Health Limits } \\
\hline & \multicolumn{2}{|c|}{ Amount of Work } & \multicolumn{2}{|c|}{ Kind of Work } \\
\hline & Yes & No & Yes & No \\
\hline White Men $(N)$ & 110 & 1,625 & 138 & 1,597 \\
\hline Spend more than 10 minutes/day on health problems & 31.41 & $3.24^{* *}$ & 32.41 & $2.65^{* *}$ \\
\hline Health problems limit social activities & 4.79 & $5.78^{* *}$ & 4.93 & $5.79^{* *}$ \\
\hline Health limits ability to climb stairs & 1.66 & $1.06^{* *}$ & 1.58 & $1.05^{* *}$ \\
\hline Health limits moderate activities & 1.64 & $1.04^{* *}$ & 1.58 & $1.04^{* *}$ \\
\hline Assessment of general health & 3.19 & $2.13^{* *}$ & 3.11 & $2.12^{* *}$ \\
\hline White Women (N) & 194 & 1,642 & 230 & 1,606 \\
\hline Spend more than 10 minutes/day on health problems & 31.46 & $4.07^{* *}$ & 30.97 & $3.53^{* *}$ \\
\hline Health problems limit social activities & 4.42 & $5.66^{* *}$ & 4.60 & $5.66^{* *}$ \\
\hline Health limits ability to climb stairs & 1.88 & $1.11^{* *}$ & 1.77 & $1.11^{* *}$ \\
\hline Health limits moderate activities & 1.87 & $1.07^{* *}$ & 1.78 & $1.06^{* *}$ \\
\hline Assessment of general health & 3.36 & $2.09^{* *}$ & 3.21 & $2.08^{* *}$ \\
\hline Black Men $(N)$ & 116 & 919 & 124 & 911 \\
\hline Spend more than 10 minutes / day on health problems & 34.02 & $3.75^{* *}$ & 33.78 & $2.54^{* *}$ \\
\hline Health problems limit social activities & 4.59 & $5.75^{* *}$ & 4.62 & $5.76^{* *}$ \\
\hline Health limits ability to climb stairs & 1.77 & $1.06^{* *}$ & 1.75 & $1.06^{* *}$ \\
\hline Health limits moderate activities & 1.74 & $1.05^{* *}$ & 1.69 & $1.05^{* *}$ \\
\hline Assessment of general health & 3.29 & $2.16^{* *}$ & 3.27 & $2.15^{* *}$ \\
\hline Black Women $(N)$ & 187 & 951 & 198 & 940 \\
\hline Spend more than 10 minutes / day on health problems & 22.99 & $3.91^{* *}$ & 23.07 & $3.76^{* *}$ \\
\hline Health problems limit social activities & 4.63 & $5.55^{* *}$ & 4.61 & $5.56^{* *}$ \\
\hline Health limits ability to climb stairs & 1.91 & $1.17^{* *}$ & 1.91 & $1.17^{* *}$ \\
\hline Health limits moderate activities & 1.76 & $1.08^{* *}$ & 1.76 & $1.07^{* *}$ \\
\hline Assessment of general health & 3.42 & $2.44^{* *}$ & 3.42 & $2.43^{* *}$ \\
\hline
\end{tabular}

Note: Values shown are the mean for each variable (see text for a description of categories)

** denotes that the difference between respondents experiencing a health limitation and respondents not experiencing a health limitation is statistically significant at $\mathrm{p}<.05$.

of stairs?"); (4) an indicator, ranging from $1=$ not limited at all to $3=$ limited a lot, of whether health problems limit participation in moderate activities ("Does your health limit you in your ability to participate in moderate activities, such as moving a table, pushing a vacuum cleaner, bowling or playing golf?"); and (5) the respondent's assessment of their health, ranging from $1=$ excellent to $5=$ poor ("In general, would you say your health is...").

The results in Table 2 show that the two longitudinal measures of health used in this analysis are closely linked with other measures of health in the expected direction. In the survey year closest to the year in which they turn 40 , respondents who note that their health limits either the amount or kind of work they can do are significantly more likely to spend more than 10 minutes per day attending 
to health problems, are more likely to note that their health limits their social activities, their ability to climb stairs, or ability to participate in moderate activities. Their self-reported health is also significantly lower than respondents who do not list any limitations in the amount and kind of work they can do. Taken together, these results strengthen confidence in the ability of the two measures used in this analysis to distinguish between individuals who are truly suffering from a limitation in health and those who are not.

Finally, because I make use of a fixed-effects procedure, only cases in which there was a change in health status provide information for the likelihood estimator. Because the sample I use is relatively young, one might question what fraction of the many intervals in the NLSY-79 database can be attributed to respondents who never experience a change in health status (overwhelmingly, these are respondents who report in all intervals that they have no health limitations, with a few respondents reporting a health limitation in all intervals). For white men, estimates in this article are based on 750 individuals who have ever experienced a change in health status covering 22.6 percent of intervals for limitations in kind of work and 18.2 percent of intervals for limitations in amount of work. For white women, estimates are based on 1,214 individuals having ever experienced a change in health status covering 30.6 percent of intervals for limitations in kind of work and 25.8 percent of intervals for limitations in amount of work. For black men, estimates are based on 484 men ever experiencing a change in health status covering 27.4 percent of intervals for kind of work and 24.6 percent of intervals for amount of work. For black women, estimates are based on 664 individuals ever experiencing a change in health status covering 39.8 percent of intervals for kind of work and 34.9 percent of intervals for amount of work.

\section{MULTIVARIATE ANALYSIS}

Tables 3 and 4 represent basic multivariate models for health limitations in kind of work and amount of work, respectively. The coefficients shown represent the relative odds that a respondent reports a health limitation in ability to work. Thus, coefficients less than 1.0 indicate positive effects on health, and coefficients greater than 1.0 indicate negative effects on health. As is normally the case with logistic regression models, the percent change in the odds of shifting health status can be calculated by subtracting 1.0 from the coefficient in question and multiplying by 100 .

The results in Table 3 show several consistent findings for limitations in kind of work that can be performed. First, the effects of current family status on health are much different for white men and women. In particular, marriage is linked to a smaller likelihood of health limitations among white men and a larger likelihood of health limitations among white women. Married white men are about 25 percent less likely than white men never in a union to report a health limitation in kind of work. Married white women are 60 percent more likely than white women never in a union to report a health limitation. Compared to their counterparts never in a union, cohabiting white women are also about 30 percent more likely to report a health limitation. For blacks neither marriage nor cohabitation 
TABLE 3

Multivariate Conditional Logistic Regression Models Linking Kind of Work That Can Be Performed to Family Life Course Statuses and Transitions and Control Variables: Odds Ratios

\begin{tabular}{|c|c|c|c|c|}
\hline & \multicolumn{2}{|c|}{ Whites } & \multicolumn{2}{|c|}{ Blacks } \\
\hline & Men & Women & Men & Women \\
\hline \multicolumn{5}{|l|}{ Current Status } \\
\hline Married & $0.748^{* *}$ & $1.600^{* *}$ & 0.855 & 1.148 \\
\hline Divorced & 0.851 & 1.226 & 0.803 & 1.279 \\
\hline Cohabiting & 0.934 & $1.321^{*}$ & 0.903 & 0.969 \\
\hline Children & 1.131 & $0.310^{* *}$ & 0.753 & $0.375^{* *}$ \\
\hline \multicolumn{5}{|l|}{ Transition } \\
\hline Marry & 0.875 & 1.018 & 0.942 & $1.407^{* *}$ \\
\hline Divorce & 1.152 & 1.009 & 1.141 & $0.499^{* *}$ \\
\hline Cohabit & $0.501^{* *}$ & 0.847 & 0.875 & 1.183 \\
\hline End cohabitation & 1.435 & 0.814 & 0.890 & 1.018 \\
\hline Gain child & 0.945 & 0.969 & 0.734 & 1.225 \\
\hline Lose child & 0.829 & $0.573^{* *}$ & 0.837 & 0.809 \\
\hline \multicolumn{5}{|l|}{ Controls } \\
\hline Education & 0.940 & $0.885^{* *}$ & $0.841^{* *}$ & 0.985 \\
\hline Enrolled & 0.974 & $0.742^{* *}$ & 0.793 & $0.625^{* *}$ \\
\hline Weeks worked past year & $0.977^{* *}$ & $0.989^{* *}$ & $0.979^{* *}$ & $0.982^{* *}$ \\
\hline Cumulative experience & $0.997^{* *}$ & $0.998^{* *}$ & $0.997^{* *}$ & $0.998^{* *}$ \\
\hline Log family income & 1.000 & 1.002 & $1.019^{*}$ & 0.999 \\
\hline Age & $1.017^{* *}$ & $1.011^{* *}$ & $1.014^{* *}$ & $1.012^{* *}$ \\
\hline LR chi-square/df & $518.9 / 16$ & $662.8 / 16$ & $498.4 / 16$ & $676.9 / 16$ \\
\hline
\end{tabular}

${ }^{*} p<.10 ; * * p .05$.

is linked to limitations in kind of work for either sex. Contrary to other research, being divorced is not significantly associated with health in these data.

The results in Table 3 also show that there is a major distinction between men and women in the relationship between parenthood status and health. For both blacks and whites, the presence of children is unrelated to the health limitations of men, while it is positively related to the health limitations of women. Compared to women without children living in the household, white women with children who reside with them are about 70 percent less likely to report a health limitation in the kind of work they can do, while the figure for black women is about 63 percent less likely.

There is less consistent evidence that family-related transitions affect health limitations. For white men, movement into a cohabiting union is linked to better health. For white women, losing the presence of a child is associated with better health. For black women, a transition into marriage is related to worse health, while a divorce is linked to better health. For black men, no family life course transitions are related to limitations in the kind of work that can be performed. As indicated in the section below on extensions to the analysis, none of these transitions had effects that persisted over time. Thus, the effects of experiencing a transition 
TABLE 4

Multivariate Conditional Logistic Regression Models Linking Amount of Work That Can Be Performed to Family Life Course Statuses and Transitions and Control Variables: Odds Ratios

\begin{tabular}{|c|c|c|c|c|}
\hline & \multicolumn{2}{|c|}{ Whites } & \multicolumn{2}{|c|}{ Blacks } \\
\hline & Men & Women & Men & Women \\
\hline \multicolumn{5}{|l|}{ Current Status } \\
\hline Married & $0.762^{* *}$ & $1.694^{* *}$ & $0.719^{*}$ & 1.082 \\
\hline Divorced & 0.848 & $1.299^{* *}$ & 0.792 & $1.277^{*}$ \\
\hline Cohabiting & 1.306 & 1.057 & 0.984 & 0.947 \\
\hline Children & 1.037 & $0.304^{* *}$ & 0.951 & $0.436^{* *}$ \\
\hline \multicolumn{5}{|l|}{ Transition } \\
\hline Marry & 0.838 & 0.948 & 0.801 & 1.232 \\
\hline Divorce & 1.225 & 1.081 & 1.287 & $0.589^{* *}$ \\
\hline Cohabit & $0.514^{* *}$ & 1.065 & 0.668 & 1.099 \\
\hline End cohabitation & 1.085 & 0.911 & 0.783 & 0.795 \\
\hline Gain child & 1.053 & 1.016 & 0.968 & 1.166 \\
\hline Lose child & 0.893 & $0.494^{* *}$ & 1.202 & 0.893 \\
\hline \multicolumn{5}{|l|}{ Controls } \\
\hline Education & 0.956 & $0.913^{* *}$ & 0.920 & 1.038 \\
\hline Enrolled & 1.143 & $0.845^{*}$ & 0.942 & 0.819 \\
\hline Weeks worked past year & $0.977^{* *}$ & $0.989^{* *}$ & $0.979^{* *}$ & $0.980^{* *}$ \\
\hline Cumulative experience & $0.996^{* *}$ & $0.999 * *$ & $0.997^{* *}$ & $0.999 * *$ \\
\hline Log family income & $0.986^{*}$ & 0.994 & $1.023^{* *}$ & 0.999 \\
\hline Age & $1.016^{* *}$ & $1.010^{* *}$ & $1.014^{* *}$ & $1.010^{* *}$ \\
\hline LR chi-square / $d f$ & $573.3 / 16$ & $660.7 / 16$ & $497.2 / 16$ & $652.7 / 16$ \\
\hline
\end{tabular}

${ }^{*} p<.10 ;{ }^{* *} p<.05$.

noted in Table 3 are short-lived (lasting no more than the duration between survey intervals) and do not indicate substantial alteration in the health trajectories implied by family and parent status.

The results shown in Table 4 for limitations in amount of work that can be performed largely reflect those in Table 3 . In particular, marriage is beneficial to the health of white men and detrimental to the health of white women. Cohabitation has no statistically significant effects on health limitations. One minor difference is that the coefficient for marriage among black men is now marginally statistically significant, indicating better health (about 28 percent less likely to experience a health condition that limits their amount of work). Children are once again unrelated to the health status of men but are negatively related to health limitations among women of both races. In terms of transitions, moving into cohabitation is positively related to the health of white men, losing the presence of a child in the household is positively related to the health of white women, and divorce is positively related to the health of black women. Thus, as was the case for kind of work, the pattern of effects for transitions does not show a consistent pattern. Nor was there any indication that the effects of transitions persisted over time (see the section on extensions below). 


\section{EXTENSION}

I tested whether the amount of time spent in a particular status (measured as duration since the last transition marking the respondent's movement into that status). Several authors have suggested that duration spent in a status can alter the effect of that status on health (Bennett 2006; Meadows et al. 2008; Williams and Umberson 2004). None of these models fit the data better than the models shown in Tables 3 and 4, however (using standard chi-square tests obtained by subtracting the model chi-square values for hierarchical models; results not shown).

\section{DISCUSSION}

The results indicate that the family life course is linked to health limitations and these linkages vary according to sex and race. Differences that occur according to sex are particularly dramatic. Marriage reduces health limitations for men, while it increases health limitations for women. The effect of marriage on the health of men is consistent with prior findings and likely reflects the greater gains in socioemotional assistance and social networks associated with marriage for men (Beckett and Elliott 2002; Umberson 1987; 1992). The fact that controls for important socioeconomic variables such as education, income, and labor force participation failed to explain the negative relationship between marriage and health for men provides further support for the notion that differences in social networks and monitoring of health-related behaviors are the mechanisms through which the relationship is generated.

The positive effect of marriage on health limitations for women was unexpected in that prior research has generally found either no effect for women or a small positive effect on overall health (usually smaller than for men). Only Wu and Hart (2002) report a negative effect of marriage on overall health for women. One mechanism potentially driving the observed negative effect is the traditional caregiving role assumed by many women, which often means that they experience increased stress when providing care for multiple family members (e.g., spouse, children, and elderly parents) (Allen, Blieszner, and Roberto 2000; Loomis and Booth 1995), negatively impacting their health.

A second difference between men and women is that, consistent with prior research (Evenson and Simon 2005; Nomaguchi and Milkie 2003), children are not linked to the health limitations of men. For women, however, having children is strongly and negatively related to their health limitations. On one hand, this may be the result of selectivity in that healthier women are selected into parenthood. On the other hand, it may be the case that women with children are less likely to engage in risky behaviors (e.g., smoking, excessive alcohol consumption) that hold negative health consequences.

The major race difference is located among women and reflects the fact that being married is positively related to health limitations for blacks but not whites (although marriage also appears to be more tenuously linked to the health limitations of black men than white men). This finding is consistent with the notion that marital status is less consequential for the health status of black women than for white women. One possible mechanism for this effect rests in prior literature that suggests that black women are less likely than white women to be negatively 
affected by the multiple and often conflicting caregiving roles associated with married life (Marcussen and Piatt 2005).

Although some transitions between statuses appear to have an effect on health limitations, they are short-lived effects, indicating little support for stress as a mechanism generating negative health outcomes. Moreover, there is no clear pattern of effects of transitions across race and sex groups. Thus, it appears to be the case that status in the family life course, more than transitions, is linked to the health limitations of men and women. These differences are not linked to differences in age, education, work experience, and income associated with the family life course. Rather, variation in the demands associated with different roles, and how these demands are differentially interpreted by various race and sex groups, and the access that these roles provide to social networks seem to provide the routes along which differences in health occur.

\section{CONCLUSION}

The results presented in this article demonstrate the relationship between the family life course of men and women and health limitations. Perhaps the most striking finding is that marriage is negatively linked to health limitations among men, while it is positively related to health limitations among women. Unlike marriage, cohabitation does not appear to be consistently linked to health limitations among young men and women. Overall, the results also indicate that status in the family life course is more important than transitions between statuses.

This study extends prior research in several ways. First, I use consistent measures of health status taken over a long period of time (25 years). Respondents are observed both before and after they hold different statuses in the life course. Second, I include a detailed set of family life course statuses and transitions that include marriage, cohabitation, and parenthood. Third, I use a fixed-effects procedure that minimizes the likelihood that selectivity generates the observed effects.

Despite its strengths, this study still suffers from weaknesses. One weakness rests in the measures of health. Even though a consistent set of measures was used over all waves of the NLSY-79, the questions used pertain to a limited domain of health: health as it tied to the amount and kind of work that can be performed. There is no information about the type of health problems that limit work, nor is there any information about the beginning and ending dates of limitations or their severity. I also assumed that physical health, rather than mental health, primarily limited a respondent's ability to work. Yet it may be the case that mental health issues also play a role in limiting a respondent's ability to work. Using the NLSY-79 data, I am also unable to directly measure the underlying mechanisms that might lead the family life course to be linked to health. Finally, subsequent research should seek to extend the analysis beyond whites and blacks.

Despite these limitations, the data clearly show a linkage between the family life course and health and that these linkages vary considerably by sex. Subsequent research needs to better detail the mechanisms underlying these associations. Subsequent research also needs to extend these findings to older ages in the life course. Although the NLSY-79 includes data over a long period of time, the results are limited to respondents in their early 40 s. 


\section{NOTE}

1. Thus, the dependent variable does not represent change in health status. Rather it represents the current value of health status in an interval for any respondent who has ever experienced a change in health status.

\section{REFERENCES}

$\rightarrow$ Allen, Kathryn, Rosemary Blieszner, and Karen Roberto. 2000. "Families in the Middle and Later Years: A Review and Critique of Research in the 1990s." Journal of Marriage and the Family 62(4):911-26.

Allison, Paul D. 2005. Fixed Effects Regression Methods for Longitudinal Data Using SAS. Cary, NC: SAS Institute.

$\rightarrow$ Amato, Paul R. 2000. "The Consequences of Divorce for Adults and Children." Journal of Marriage and the Family 62(4):1269-87.

_ and Alan Booth. 1997. A Generation at Risk: Growing Up in an Era of Family Upheaval. Cambridge, MA: Harvard University Press.

$\rightarrow \longrightarrow$, Nancy S. Landale, Tara C. Havasevich-Brooks, Alan Booth, David J. Eggebeen, Robert Schoen, and Susan M. McHale. 2008. "Precursors of Young Women's Family Formation Pathways." Journal of Marriage and Family 70(5):1271-85.

Beckett, Megan and Marc N. Elliott. 2002. "Does the Association between Marital Status and Health Vary by Sex, Race, and Ethnicity?" Working Paper Series 02-08, Labor and Population Program. Santa Monica, CA: RAND Corporation.

Belsky, Jay and John Kelly. 1994. The Transition to Parenthood. New York: Delacourte.

$\rightarrow \longrightarrow$, Mary E. Lang, and Michael Rovine. 1985. "Stability and Change in Marriage across the Transition to Parenthood: A Second Study." Journal of Marriage and the Family 47(4):855-65.

$\rightarrow$ Bennett, Kate M. 2006. "Does Marital Status and Marital Status Change Predict Physical Health in Older Adults?" Psychological Medicine 36(9):1313-20.

Broman, Clifford L. 1991. "Gender, Work-Family Roles, and Psychological Well-Being of Blacks." Journal of Marriage and the Family 53(2):509-20.

Brown, Susan L. 2000. "The Effect of Union Type on Psychological Well-Being: Depression among Cohabitors Versus Marrieds." Journal of Health and Social Behavior 41(3): 241-55.

Cheung, Yin B. 1998. "Can Marital Selection Explain the Differences in Health between Married and Divorced People? Results from a Longitudinal Study of a British Birth Cohort." Public Health 112(2):113-17.

$\rightarrow-$ and Andy Sloggett. 1998. "Health and Adverse Selection into Marriage: Evidence from a Study of the 1958 British Birth Cohort." Public Health 112(5):309-11.

Cowan, Carolyn Pape and Philip A. Cowan. 2000. When Partners Become Parents: The Big Life Change for Couples. Mahwah, NJ: Lawrence Erlbaum.

$\rightarrow$ DeKlyen, Michelle, Jeanne Brooks-Gunn, Sara McLanahan, and Jean Knab. 2006. "The Mental Health of Married, Cohabiting, and Non-Coresident Parents with Infants." American Journal of Public Health 96(10):1836-41.

Depner, Charlene E. and Berit Ingersoll-Dayton. 1985. “Conjugal Social Support: Patterns in Later Life." Journal of Gerontology 40(6):761-66.

$\rightarrow$ Evenson, Ranae J. and Robin W. Simon. 2005. "Clarifying the Relationship between Parenthood and Depression." Journal of Health and Social Behavior 46(4):341-58.

Gallagher, Sally K. and Naomi Gerstel. 2001. "Connections and Constraints: The Effects of Children on Caregiving." Journal of Marriage and the Family 55(2):598-607. 
$\rightarrow$ Gerdingen, Dwenda K. and Bruce A. Center. 2005. "First-Time Parents' Postpartum Changes in Employment, Childcare, and Housework Responsibilities." Social Science Research 34(1):103-16.

$\rightarrow$ Gerstel, Naomi. 1988. "Divorce, Gender, and Social Integration." Gender and Society 2(3): 343-67.

$\rightarrow$ Glass, Jennifer and Tetsushi Fujimoto. 1994. "Housework, Paid Work and Depression among Husbands and Wives." Journal of Health and Social Behavior 35(1):179-91.

$\rightarrow$ Goldman, Noreen. 1993. "Marriage Selection and Mortality Patterns: Inferences and Fallacies." Demography 30(2):189-208.

$\rightarrow$ Goldsteen, Karen and Catherine E. Ross. 1989. "The Perceived Burden of Children." Journal of Family Issues 10(4):504-26.

$\rightarrow$ Gove, Walter R. and Hee-Choon Shin. 1989. "The Psychological Well-Being of Divorced and Widowed Men and Women." Journal of Family Issues 10(1):122-44.

$\rightarrow \mathrm{Hu}$, Yuanreng and Noreen Goldman. 1990. "Mortality Differentials by Marital Status: An International Comparison." Demography 27(2):233-50.

$\rightarrow$ Johnson, David. 2005. "Two-Wave Panel Analysis: Comparing Statistical Methods for Studying the Effects of Transitions." Journal of Marriage and the Family 67(4):1061-75.

$\rightarrow$ Joung, Inez M. A., H. Dike van de Mheen, Karien Stronks, Frans W. A. van Poppel, and Johan P. Mackenback. 1998. "A Longitudinal Study of the Health Selection in Marital Transitions." Social Science and Medicine 46(3):425-35.

$\rightarrow$ Kenney, Catherine T. and Sara McLanahan. 2006. "Why Are Cohabiting Relationships More Violent than Marriages?" Demography 43(1):127-40.

Landry, Bart. 2000. Black Working Wives: Pioneers of the American Family Revolution. Berkeley, CA: University of California Press.

$\rightarrow$ Lillard, Lee A. and Linda J. Waite. 1995. “Til Death Do Us Part: Marital Disruption and Mortality." American Journal of Sociology 100(5):121-56.

$\rightarrow$ Loomis, Laura and Alan Booth. 1995. "Multigenerational Caregiving and Well-Being: The Myth of the Beleaguered Sandwich Generation." Journal of Family Issues 16(2):131-48.

$\rightarrow$ Lorenz, Fredrick O., K. A. S. Wickrama, Rand D. Conger, and Glen H. Elder. 2006. "The Short-Term and Decade-Long Effects of Divorce on Women's Midlife Health." Journal of Health and Social Behavior 47(2):111-25.

$\rightarrow$ Manning, Wendy D. and Pamela J. Smock. 2002. "First Comes Cohabitation and Then Comes Marriage? A Research Note." Journal of Family Issues 23(8):1065-87.

$\rightarrow$ Marcussen, Kristen. 2005. "Explaining Differences in Mental Health between Married and Cohabiting Individuals." Social Psychology Quarterly 68(3):239-57.

$\rightarrow-$ and Liz Piatt. 2005. "Race Differences in the Relationship between Role Experiences and Well-Being." Health: An Interdisciplinary Journal for the Social Study of Health, Illness and Medicine 9(3):379-402.

$\rightarrow$ McQuillan, Julia, Arthur L. Greil, Lynn White, and Mary Casey Jacob. 2003. "Frustrated Fertility: Infertility and Psychological Distress among Women." Journal of Marriage and Family 65(4):1007-18.

$\rightarrow$ Meadows, Sara O., Sara S. McLanahan, and Jeanne Brooks-Gunn. 2008. "Stability and Change in Family Structure and Maternal Health Trajectories." American Sociological Review 73(2):314-34.

Mirowsky, John. 2002. "Parenthood and Health: The Pivotal and Optimal Age at First Birth." Social Forces 81(1):315-49.

$\rightarrow$. 2006. "Age at First Birth, Health, and Mortality." Journal of Health and Social Behavior 46(1):32-50.

$\rightarrow$ Nock, Steven L. 1995. "A Comparison of Marriages and Cohabiting Relationships." Journal of Family Issues 16(1):53-76. 
$\rightarrow$ Nomaguchi, Kei M. and Melissa A. Milkie. 2003. "Costs and Rewards of Children: The Effects of Becoming a Parent on Adult's Lives." Journal of Marriage and Family 65(2):356-74.

Peters, Arnold and Aart C. Liefbroer. 1997. "Beyond Marital Status: Partner History and Well-Being in Old Age." Journal of Marriage and Family 59(3):687-99.

Popenoe, David. 1996. Life without Father: Compelling New Evidence that Fatherhood and Marriage Are Indispensable for the Good of Children and Society. New York: Martin Kessler Books.

Rogers, Richard G. 1995. "Marriage, Sex, and Mortality." Journal of Marriage and Family 57(2):515-26.

Ross, Catherine E. 1995. “Reconceptualizing Marital Status as a Continuum of Social Attachment." Journal of Marriage and Family 57(1):129-40.

- John Mirowsky, and Karen Goldsteen. 1990. "The Impact of Family on Health: The Decade in Review." Journal of Marriage and Family 52(4):1059-78.

Sayer, Liana C., Suzanne M. Bianchi, and John P. Robinson. 2004. "Are Parents Investing Less in Children: Trends in Mothers' and Fathers' Time with Children." American Journal of Sociology 110(1):1-43.

Teachman, Jay D., Lucky M. Tedrow, and Kyle D. Crowder. 2000. “The Changing Demography of America's Families." Journal of Marriage and Family 62(4):1234-46.

$\rightarrow$ Turner, Heather A. 1994. "Gender and Social Support: Taking the Bad with the Good?" Sex Roles: A Journal of Research 30(7-8):521-41.

Umberson, Debra. 1987. "Family Status and Health Behaviors: Social Control as a Dimension of Social Integration." Journal of Marriage and Family 28(3):306-19.

$\rightarrow$ _ 1992. "Gender, Marital Status, and the Social Control of Health Behavior." Social Science and Medicine 34(8):907-17.

$\rightarrow$ Wade, Terrance J. and David J. Pevalin. 2004. "Marital Transitions and Mental Health." Journal of Health and Social Behavior 45(2):155-70.

$\rightarrow$ Waite, Linda. 1995. “Does Marriage Matter?" Demography 32(4):483-507.

$\rightarrow$ Waldron, Ingrid, Christopher C. Weiss, and Mary Elizabeth Hughes. 1998. "Interacting Effects of Multiple Roles on Women's Health." Journal of Health and Social Behavior 39(3):216-36.

Williams, Kristi, Sharon Sassler, and Lisa M. Nicholson. 2008. “For Better or for Worse? The Consequences of Marriage and Cohabitation." Social Forces 86(4):1481-511.

$\rightarrow-$ and Debra Umberson. 2004. "Marital Status, Marital Transitions, and Health: A Gendered Life Course Approach." Journal of Health and Social Behavior 45(1):81-98.

Wood, Robert G., Brian Goesling, and Sara Avellar. 2007. "The Effects of Marriage on Health." U.S. Department of Health and Human Services, Office of the Assistant Secretary for Planning and Evaluation, Office of Human Services Policy. http://aspe.hhs.gov / hsp/07/marriageonhealth/index.htm.

$\rightarrow \mathrm{Wu}$, Zheng and Randy Hart. 2002. "The Effects of Marital and Nonmarital Union Transition on Health." Journal of Marriage and Family 64(2):420-32.

$\rightarrow$ _ Margaret J. Penning, Michael S. Pollard, and Randy Hart. 2003. "In Sickness and in Health: Does Cohabitation Count?" Journal of Family Issues 24(6):811-38.

Wyke, Sally and Graeme Ford. 1992. "Competing Explanations for Associations between Marital Status and Health." Social Science and Medicine 34(5):523-32.

Zhang, Zhenmei and Mark D. Hayward. 2006. "Gender, the Marital Life Course, and Cardiovascular Disease in Late Midlife." Journal of Marriage and Family 68(3):639-57. 

All use subject to JSTOR Terms and Conditions 